\title{
Da rivalidade à responsabilidade: reflexões sobre a justiça restaurativa a partir da psicanálise
}

\author{
Miriam Debieux Rosa ${ }^{*}$, Marta Cerruti \\ Instituto de Psicologia, Universidade de São Paulo, São Paulo, SP, Brasil
}

Resumo: Várias modalidades de intervenção têm incluído as relações horizontais, que apostam na circulação da palavra como condição de inscrição de uma distância capaz de aproximar e produzir um laço com o outro. Neste trabalho, iremos contemplar as funções do outro, abordar a relação com o semelhante, destacando os elementos levantados por Lacan em Hamlet, demonstrando que é para além da rivalidade com o semelhante que entra em jogo a realização do desejo de Hamlet (Lacan, 1959/86). Nossa estratégia será pela apresentação de duas cenas de intervenção junto a adolescentes em conflito com a lei, uma delas em um processo de Justiça Restaurativa. Vamos tirar consequências desta análise no que se refere à possibilidade de condições da horizontalidade nas relações, particularmente nas intervenções junto a adolescentes em conflito com a lei, tendo em vista a responsabilidade como uma construção que se opera no encontro com o outro.

Palavras-chave: psicanálise, justiça restaurativa, adolescente em conflito com a lei, responsabilidade, semelhante.

\section{Proscênio'}

Temos debatido sobre as modalidades de resistência subjetiva e política às estratégias de poder no contemporâneo. Tal resistência supõe uma práxis que visa o deslocamento do gozo mortífero e monitorado politicamente para o resgate da experiência compartilhada do mundo, na qual os processos coletivos e a reabilitação do espaço público possam tornar possível a criação de mecanismos de resistência contra a submissão ao poder soberano, bem como possibilitar a construção de projetos comuns (Rosa, Vicentin, \& Catrolli, 2009). Neste trabalho, iremos contemplar as funções do outro que, para além de formações de massas igualitárias ou de hordas, pode constituir-se como uma modalidade de laço que "com sentimentos da ordem do respeito, realiza (-se) toda uma assunção afetiva do próximo" (Lacan, 1948/1998, pp. 119-120). Várias modalidades de intervenção têm incluído as relações horizontais como interessantes ao sujeito e ao laço com uma polis menos privatizada - intervenções em grupo, dentre elas a Justiça Restaurativa, que apostam na circulação da palavra como condição de inscrição de uma distância capaz, paradoxalmente, de aproximar e produzir um laço com o outro.

As práticas restaurativas ressaltam a importância do processo dialogal na resolução de conflitos, questionando o paradigma da eficácia de respostas de natureza estritamente penal. O tratamento jurídico dispensado pelo

* Endereço para correspondência: debieux@terra.com.br

1 Proscénio (do latim proscenium) é a parte do palco que se localiza na frente do cenário, junto da ribalta, sendo então o espaço que separa a plateia do palco. O proscênio tem a função de permitir que aqueles que se situam nas primeiras fileiras possam ter um bom campo de visão daquilo que se passa no palco. sistema retributivo cria um campo que tende para uma visão totalizadora: "infrator", "autor de ato infracional" são posições que acabam por excluir qualquer singularidade do sujeito e, dessa maneira, conferem aos autores do ato um positivismo identificatório.

O proceder restaurativo, ao interrogar o dogma do ser ontologizado, abre novas perspectivas para o entendimento da responsabilização do autor do ato infracional. E isso por meio do diálogo, acreditando que, no exercício do encontro, a palavra é instrumento para a construção de novos sentidos. Se a responsabilidade implica responder ao outro pela não-indiferença, o que se busca nesse proceder é, antes de tudo, a restauração dos laços. Nossa proposta é encaminhar a discussão tendo em conta que, se a responsabilidade é algo que se constrói no encontro, a importância do outro deve ser mais bem entendida. O que significa, de fato, que o homem é um ser social? Quais são as consequências da constatação de que não existe um eu sem você?

Nossa intenção não é discorrer sobre a metodologia utilizada na Justiça Restaurativa propriamente dita. Pretendemos apontar como a instauração de um novo paradigma, que leva em conta o espaço coletivo, sem se circunscrever a um tratamento intrassubjetivo para a assunção da responsabilidade, pode promover mudanças significativas e trazer à luz novas formas de abordagem naquilo que se refere ao jovem em conflito com a lei.

Há, então, que se considerar o lugar do semelhante na estrutura de um sujeito, lugar esse mais além de ele ser um possível rival. Sabemos que o sujeito se inscreve em uma topologia que não possui interior nem exterior e o que determina a representação de um sujeito em cada contexto é a 
maneira como o outro me reconhece ou não, me legitima ou não. Isso porque o desamparo estrutural do homem supõe uma relação de dependência desde o princípio. A existência do outro, seus cuidados e sua voz, são condições necessárias, pois é por meio de tais cuidados que a demanda de amor pode vir a engendrar o objeto de desejo. Lacan (1968-1969/2008) aponta no Seminário "De um outro ao outro", que "o próximo é a eminência intolerável do gozo" (p. 219). O que está em pauta nessa suposição é o suporte de uma presença que tanto pode ser obstáculo como viabilizadora, impedimento ou passagem para a sobrevivência do bem comum.

Nossa estratégia de análise será pela exposição de elementos de duas cenas de intervenção junto a adolescentes em conflito com a lei, que serão cotejadas com a chamada cena do cemitério, em Hamlet, tal qual analisada por Lacan. Vamos abordar a relação com o semelhante destacando os elementos levantados por Lacan em Hamlet, demonstrando que é para além da rivalidade com o semelhante que se joga o drama da realização do desejo de Hamlet (Lacan, 1959/1986). Tendo como ponto central da discussão o lugar ocupado por Laerte diante da morte de Ofélia, veremos a importância dessa cena para o rompimento da alienação de Hamlet. Vamos tirar consequências desta análise no que se refere à possibilidade e condições da horizontalidade nas relações e da responsabilização.

\section{Hamlet segundo Lacan}

O drama de Hamlet é antes de tudo um drama que concerne à existência do sujeito, que lhe impõe uma escolha: to be or not to be (Lacan, 1959/1986), envolvendo o seu ser. É um drama que implica o desejo, um drama subjetivo e existencial, que coloca em cena o desejo enquanto desejo do Outro, expresso na indagação Chè vuoi? Hamlet nos dá um exemplo de como é possível que ocorra o reconhecimento do si mesmo, passando pelo outro especular, a fim de reencontrar, de reconstituir o objeto causa de seu desejo.

Segundo Chatelard (2001),

desde Freud, o termo imagem - Bild - e sua função primordial entre o sujeito e seu semelhante já tinha um lugar importante na constituição do sujeito. Com Lacan, uma passagem se efetua entre a imagem, tal como foi concebida por Freud, e o que resta dessa imagem como não especular. (p. 341)

A identificação será concebida por Freud como a forma original e primeira da constituição do laço, sendo por isso considerada como prévia a qualquer escolha objetal: o eu da criança se serve do mecanismo da identificação em uma tentativa de resolver o enigma do seu ser: afinal, quem sou eu? E é pela via da identificação que os valores nas trocas simbólicas subsequentes serão estabelecidos. Este eu, segundo Freud, nasce de uma operação psíquica que corresponde ao narcisismo primário, o qual Lacan abordou na metáfora do "estádio do espelho": é a definição do eu como projeção da superfície corporal, tal como Freud aponta em seu trabalho "O Ego e o Id" (Freud, 1923/1980b) que dá subsídios para que Lacan teorize a alienação fundamental do sujeito em uma imagem especular, uma vez que algo resta e não pode ser especularizável. Trata-se do objeto a, algo que se destaca e insiste enquanto causa do desejo.

Em seu seminário 6, O desejo e sua interpretação, Lacan (1958-1959/2002) pergunta o que é, afinal, o desejo, e qual o alcance de sua interpretação, dado que o desejo só pode ser apreendido como causa e, conforme apontado acima, seu objeto não é em absoluto espacularizável. Para Lacan, o desejo irá se originar no mesmo lugar onde o sujeito vive a experiência do desamparo. Na presença do desejo do Outro o sujeito está sem recursos e é a fantasia que oferece uma saída possível para que o sujeito se situe no mundo e opere suas relações. Dizer que o desejo humano está fixado a uma fantasia e não a um objeto supõe considerar a presença da fantasia no inconsciente, fantasia essa que emoldura os possíveis laços do sujeito com o semelhante. Segundo Safouan (2006):

Encontramos, indica Lacan, a fórmula constante da fantasia no inconsciente. Essa relação do sujeito, na medida em que é barrado, anulado pelo significante e na medida em que encontra o seu suporte no outro, é o lugar onde o sujeito mantém sua existência, mantém o véu que faz com que possa continuar a ser um sujeito que fala. (p. 90)

A questão é discriminar se o desejo do sujeito habita sua fantasia, ou então se é no ato de significar essa fantasia que o desejo se manifesta. E é a segunda hipótese que Lacan sustenta ao longo deste Seminário, razão pela qual dedica boa parte de seus esforços ao drama de Hamlet, estabelecendo as conexões entre a constituição do objeto e o luto, no qual o luto opera como uma manifestação do desejo que permite, ao fim e ao cabo, a realização de um ato.

Tomando a cena do cemitério, vemos o insuportável que é para Hamlet testemunhar Laerte expor seu luto intenso: foi pela via do ciúme do luto que uma mudança pôde ocorrer e que fez Hamlet ser capaz de cumprir o ato que seu pai deixara a seu encargo.

Ou seja, no drama de Hamlet, podemos compreender como o objeto foi constituído após ter sofrido, num primeiro tempo, uma negligência como objeto de amor, permitindo assim ao sujeito fazer um luto do objeto perdido, ou dizendo melhor, de um objeto já perdido desde o início, e abrindo-lhe o caminho em direção ao desejo. $\mathrm{O}$ luto permite ao sujeito constituir, em uma cadeia metonímica infindável, novos objetos de amor e desejo, a partir da introjeção desse objeto, como objeto perdido. Dito de outro modo, o luto é importante para que o desejo como causa possa ser reintegrado: face ao objeto perdido, só resta ao sujeito fazer seu luto, para que novos objetos possam se constituir. Por meio de Hamlet podemos ver como, do falo imaginário, chegamos ao símbólico: depois de passar pela imaginarização da perda, podemos aceder ao simbólico. No que diz respeito à relação entre o luto e o reconhecimento do desejo como causa, Lacan mostra (1958-1959/2002) 
como, após o enterro de Ofélia, finalmente Hamlet, diante de Laerte, é confrontado ao significante do desejo.

Tendo esta leitura em mente, vamos ao relato de duas cenas, nas quais os impasses são compartilhados para argumentar que a presença do semelhante propicia que uma fantasia possa se constituir no laço com o outro, dando lugar à possibilidade do desejo.

\section{Cena 1. Adolescentes e seus semelhantes}

Final de ano, último encontro de um grupo de adolescentes - com idade entre 14 a 16 anos - em medida socioeducativa, de prestação de serviços à comunidade. $\mathrm{O}$ grupo inicia com três participantes. Os outros vão chegando atrasados, alguns faltam, outros já não compareciam há um tempo. A conversa começa entrecortada, entremeada de silêncios e vazios, como sempre ocorre.

Nando cochila, Leo chega dizendo que se atrasou porque foi ajudar um amigo, e pergunta: como se pode ajudar, como fazer? Tem que bater? Foi procurar o amigo sumido nas biqueiras. Valdo comenta que seus irmãos mais velhos estão nessa também, mas que "não estou nem vendo, sabem o que estão fazendo". Nando diz que já fumou, ou melhor, é maconheiro, e volta a cochilar. A conversa dispersa mais e é proposto que façam alguns desenhos. Um integrante desenha o grupo e ri, dizendo ser a família 155 (referência ao código de roubo). Comentam que Pri não veio, não cumpriu a medida (socioeducativa).

Nando, de forma displicente comenta que um amigo morreu de overdose - cheirou 14 gramas, "será que era muito?". O burburinho cessa. A psicóloga diz: "Seu amigo morreu!". Ele se assusta e diz que estava com o amigo na hora, que tentou reanimá-lo. O clima pesado paralisa todos. Vanda chora. Carlos diz que quer parar - a mãe morreu de overdose. A psicóloga, angustiada, comenta como é difícil perder pessoas importantes da vida deles.

\section{Cena 2. Assalto com arma de brinquedo e o cír- culo restaurativo}

O adolescente, acompanhado por outro rapaz, assalta uma joalheria à mão armada. $\mathrm{O}$ adolescente participou de um círculo restaurativo, que contou com a presença de sua mãe, sua madrasta, sua irmã e a facilitadora. A ausência do pai foi justificada pelo fato de ele ser caminhoneiro. O proprietário da joalheria escreve uma carta ao adolescente, que foi lida durante o círculo. Sua mãe chorou ao escutá-la e relatou sua experiência quando foi assaltada, ressaltando o medo que sentiu depois e sua sensação de insegurança quando via alguém que se parecia com o assaltante. $\mathrm{O}$ adolescente também relatou que a funcionária o viu em um ponto de ônibus e pareceu estar em choque. Essa situação parece ter comovido muito o jovem, que afirma ter se sentido como algo que não era humano naquele momento. Conta que nunca mais gostaria de ser visto daquela maneira.
O proprietário da loja assaltada justifica sua participação na Justiça Restaurativa, mediante a escrita da carta, pois seu filho adolescente já se beneficiara dela por uma briga na escola. Quando o comunicaram sobre a proposta da Justiça Restaurativa depois do assalto, ele sentiu que não tinha como falar não: "Pelo menos na roda em que meu filho participou foi uma experiência muito positiva. Quanto ao assalto, me propuseram a roda, e eu aceitei na hora, acho que foi muito bom". A funcionária, que estava presente durante $o$ assalto, recusou-se a participar dizendo que desejava apenas seguir sua vida.

\section{A função do semelhante em cena Cena 1}

A primeira cena é composta por um grupo de adolescentes instados pela lei a responder por seus delitos. A medida prestação de serviço, neste caso, foi substituída por uma proposta de trabalho em que poderiam ter um lugar de fala. E isso com o intuito de que construíssem uma narrativa que possibilitasse um efeito de apropriação de cada um frente às suas ações, para construção de perspectivas de outras saídas. O trabalho foi permeado por forte hostilidade da parte dos funcionários da instituição em relação aos adolescentes, chamados ironicamente de "anjos". Da parte dos jovens, o que se observou em relação ao trabalho desenvolvido foi ora envolvimento, ora desânimo. Nos grupos, devido a dificuldades de estabelecerem elos entre si, por vários momentos o objeto destacado por seu valor identitário foi a maconha, como também os atos transgressores à lei e ao que chamavam de família 155 , referindo-se aos grupos que se unem para roubar como família (155 é o código penal para furto).

$\mathrm{Na}$ cena aqui relatada surge outra possibilidade de laço, de intervir: quando o outro, o amigo, está errado ou em risco. É nesse intervalo entre eu e o outro que pode ocorrer a inscrição de uma distância que torna possível a experiência do próximo, na qual não se vê nem abandono, nem invasão. Podemos ver a entrada de um rudimento de constituição de um ideal do eu - ajudar/proteger o amigo - que tem uma função apaziguadora, capaz de inscrever a distância necessária a uma assunção afetiva do próximo.

No entanto, a fragilidade do laço rompe-se diante do vazio, do sem sentido e da indiferença gerada pela morte do amigo e, por identificação, sua própria morte. $\mathrm{O}$ desamparo em sua absoluta crueza desata as tentativas de inscrição e abre o fosso da falta de significantes que possam representar o lugar de dejeto, lugar esse a que esses jovens e suas famílias são lançados em um destino trágico.

Apesar deste impacto, destacamos que os relatos da relação de cada um com as drogas, bem como a cena da morte do amigo, retiram os participantes de sua sonolência. Surge um voto de confiança no laço com a psicóloga, que não ocupa ali um braço da punição, mas procura testemunhar as tentativas de elaboração de todos. Talvez por isso Carlos lance um voto de desejo - parar com as drogas - e 
de construir outro destino, diferente do da mãe, que morreu de overdose. A droga perde o valor de objeto identitário, oferecendo oportunidade para que seu valor se desloque dando voz a um valor narcísico até então ausente.

Podemos dizer que algo do drama de Hamlet se operou, pois o objeto (o eu/narcísico e o outro) foi constituído após ter sofrido, num primeiro tempo, uma negligência como objeto de amor, permitindo assim ao sujeito fazer um luto do objeto perdido, e abrindo-lhe o caminho em direção ao desejo. $\mathrm{O}$ luto permite ao sujeito constituir um novo objeto de amor e de desejo, a partir da introjeção desse objeto, como objeto perdido. O furo da perda no real apela para o significante da falta, o falo, e o mobiliza. Esse significante vem como suplemento à ausência no Outro, marcando a impossibilidade de responder ao seu apelo, à sua demanda.

O problema neste caso é que esse significante deveria apresentar-se como o falo sob o véu, pois é por sua perda, e o consequente trabalho do luto, que ocorre um questionamento do sujeito, e que suas referências são reconstruídas. Neste caso, a crueza e a ausência do falo sob o véu, assim como a ausência de um suporte discursivo para efetuar outra passagem, do campo narcísico ao campo do desejo - podem situar o processo de elaboração reduzido apenas ao campo do imaginário.

\section{Cena 2}

À diferença da primeira cena, a cena 2 apresenta um campo em que o semelhante é diversificado e compõe diferentes lugares discursivos. Nela estão presentes sujeitos de várias faixas etárias: as figuras familiares, a vítima e o ofensor convidados a vir e assumir novas posições, a intermediação em nome da lei da facilitadora, a instituição judicial.

O ponto de partida é a cena do assalto: nela, o apoio fálico (a arma) é "de brinquedo", evidenciando sua máscara imaginária. O objeto cobiçado é um objeto exteriorizado, concreto e detém todo o valor extraído do sujeito (os objetos roubados), o que torna opacos todos os outros elementos da cena, as "vítimas". Há duas vias de restituição nessa cena: a carta endereçada como "de um pai para um filho" e o olhar da funcionária para o jovem, um olhar que não o identifica ao humano - cena que, por sua vez, reaparece no discurso da mãe sobre o medo desencadeado de um assalto sofrido por ela. Nos dois pontos há um retorno do seu ato sobre si mesmo.

Destacamos a importância do modo como o dono da loja endereça-se ao jovem na carta. Apesar do prejuízo financeiro, ele concordou em participar, pois seu próprio filho já fora beneficiado com esse procedimento. Temos aqui uma operação singular: o dono da loja foi convocado como vítima, mas respondeu a essa convocação como pai que tem uma mensagem a transmitir. Sua carta fala de sua história, semelhante a do jovem, e testemunha como alguém destituído pode, com esforço, vir a construir algo, relançando a promessa fálica ao adolescente. Além disso, opera um deslocamento do valor do objeto roubado para o valor da imagem do sujeito: o objeto é tratado como presença e ausência, como algo que se conquista e que se perde, tecendo um percurso que vai de seu valor imaginário em direção ao seu valor simbólico, uma vez que o foco é o destino do sujeito. A leitura da carta marca uma presença como texto, e não como uma presença real, o que mostra que, mesmo na ausência do seu pai, é possível que o desejo se sustente.

A leitura da carta comove a mãe do jovem, que começa a chorar por se identificar com a vítima do assalto: como já havia passado por isso sabia do medo e da impotência que a imagem do assaltante/filho provoca. Outra perda se apresenta no choro da mãe, uma perda relativa à representação social do filho, agora um assaltante. Diante do relato de sua mãe, o adolescente se recorda do olhar da caixa da joalheria em um encontro casual: aos olhos dela, ele não era humano. Desse confronto surge no adolescente uma posição - nunca mais gostaria de ser visto daquela maneira, revelando um claro movimento desidentificatório com a posição de assaltante.

Podemos pensar no jogo identificatório presente nessa cena: se a relação do sujeito ao campo do Outro começa pelo registro imaginário entre o eu e o eu ideal, esse eixo imaginário inicial ressalta, num primeiro tempo, o valor fálico, a identificação ao falo como uma exigência narcísica do sujeito. Somente num segundo tempo o sujeito contorna o campo do Outro, seu enigma, tentando assim conquistar um sentido, um nome que lhe daria a chave de seu ser de gozo, o que ele teria sido como objeto no desejo desse Outro, inaugurando a passagem do eu ideal para ideal do eu. Processa-se o luto de uma imagem, de um corpo, de um tipo de laço.

Para responder ao luto, é preciso passar pelo processo imaginário, especular e rival, num corpo a corpo, numa relação dual, para poder fazer um verdadeiro trabalho de simbolização do luto. E tal simbolização supõe a castração, que situa o sujeito em sua posição de ser falante, sua posição na linguagem, no universo da palavra. A questão do luto toma seu valor primeiramente pelo imaginário, o luto do corpo, de sua imagem, do que falta a esse corpo biológico, para passar em seguida ao luto do corpo pulsional, o que traz a possibilidade da linguagem.

A Cena Restaurativa, no processo especular entre o adolescente, seu pai e o dono da loja e entre ele, sua mãe e a moça assustada com o assaltante, pode ter possibilitado que o objeto negligenciado tenha reencontrado o caminho do seu desejo, depois de ter reconstituído o objeto. Esse processo só é possível com o trabalho do luto. O que está colocado nessa cena restaurativa lembra o que aponta Lacan (1958-1959/2002):

ao mesmo tempo na miragem do outro e através desse outro, que é Laerte, que Hamlet poderá se reencontrar diante de seu desejo, de seu drama subjetivo e humano. Pelo seu ato e por suas palavras, ele nasce finalmente como homem que carrega em si o drama do desejo. (p. 73). 
Como vimos pelo exemplo de Hamlet, o que está em jogo é a construção do Outro fictício, construído pelo sujeito em suas contingências com os demais personagens de sua história, uma construção necessária para que se encontre a via do desejo, um desejo que se inscreva no impossível, no real. Um percurso que parte de um objeto revestido de uma imagem, de uma imagem que fascina ou faz horror ao sujeito, em direção a um objeto que causa o desejo (Lacan, 1974-1975, lição de 13/05/75).

A cena restaurativa faz processar e deslocar o ganho narcísico do objeto no fascínio do eu ideal para o luto da perda desta imagem, pondo "em jogo a castração e a função do Nome do Pai como regulador e função iniciadora do simbólico e da lei, guardando as respectivas diferenças" (Lacan, 1974-1975). O sujeito tem que lidar com o luto do falo para poder, a partir daí, efetuar outra passagem, do campo narcísico ao campo do desejo.

No artigo "Luto e melancolia" (Freud, 1917/1980b), Freud já chamava a atenção sobre o mecanismo de identificação ao objeto perdido, sua incorporação. Um processo que, no drama de Hamlet, se desenvolve na cena do cemitério, a partir do momento em que Laerte manifesta seu desespero diante do túmulo de Ofélia. Por essa imagem do túmulo, Lacan nos conduz à sua fórmula (Lacan, 1959/1986), segundo a qual o que não foi simbolizado reaparece no real. No caso presente, o furo do real é representado pelo túmulo, e o "furo da perda provoca no sujeito o luto" (p. 75). Acrescenta ainda, logo em seguida: "O furo da perda no real mobiliza o significante" (p. 75), e é justamente esse furo da perda no real que apela para o significante da falta, o falo, e que o mobiliza. Esse significante vem como suplemento à ausência no Outro, marcando a impossibilidade de responder ao seu apelo, à sua demanda.

Nas duas cenas vemos como a situação de grupo, seja coordenada por uma psicóloga, seja na Justiça Restaurativa, pode promover deslocamentos importantes para elaboração do luto da imagem fálica. No entanto, na cena restaurativa, a presença de protagonistas que jogam com as funções parentais e lugares passíveis de representar o falo e a castração no campo social podem ter produzido apoios identificatórios mais substantivos. Comparando as duas cenas, vemos que a ausência desses apoios pode desembocar em desamparo e angústia, ao passo que sua presença pode reativar as marcas da castração e articular as instâncias eu ideal e ideal do eu. Nas palavras de Lacan (1959/1986):

Partamos disso, que o sujeito contorna sua relação, no campo organizado do simbólico, no qual sua exigência de amor começou a se exprimir. É na saída deste contorno, ... que se produz para ele a perda do falo, perda radical. (p. 83)

Em seu Seminário O desejo e sua interpretação, Lacan (1958-1959/2002) tirou as consequências que decorrem da concepção do desejo como efeito do aprisionamento do sujeito à cadeia significante. Isso implica que compreendamos a elaboração não como uma reconstituição do passado, tampouco como uma redução normativa, mas como um relato que é lugar de um encontro no qual está em pauta o próprio relato.

Isso indica a importância de que o sujeito esteja advertido para os diferentes lugares para os quais ele convoca o outro ou que é convocado pelo outro, a partir da estrutura de seu fantasma. Também é preciso ter em conta as consequências disso para um sujeito estruturalmente dividido entre aquilo que ele sabe e o gozo que coloca limite a esse saber. Ou seja, é estar advertido sobre as consequências de se convocar o outro em tal ou qual posição.

Com Lacan, podemos dizer que o drama de Hamlet não é somente o do desejo, da subjetividade humana, mas também do encontro com a morte, que coincide com o encontro de Hamlet com seu objeto de amor: encontro impossível, pois ele apreende o objeto somente a partir do momento em que esse objeto desaparece: "Do que se trata, no desejo, é de um objeto, não de um sujeito . . . um objeto diante do qual desaparecemos, vacilamos, desaparecemos como sujeito" (Lacan, 1948/1998, p. 226).

Trata-se, portanto, de um jogo dinâmico entre horizontalidade e verticalidade. Retornando a nossa questão, vemos que, em Hamlet, a cena do cemitério está inserida em outra cena referente ao assassinato do pai, à perda das referências da Lei e da castração. O semelhante tem sua função, mas esta não é única para constituir a modalidade de laço que Lacan assinala: "com sentimentos da ordem do respeito, realiza(-se) toda uma assunção afetiva do próximo." (Lacan, 1948/1998, pp. 119-120). O desvendamento e a implicação na cena, tanto dos pares como da referência de todos à Lei, é o que permite reposicionar o sujeito adolescente no seu processo.

Quando e se esse compromisso não se estabelece não há formato algum que provoque e sustente uma possibilidade de responsabilização. Assim, podemos concluir que não se trata de priorizar uma ou outra ferramenta de trabalho, mas de sustentar o compromisso com a responsabilização coletiva. 


\section{From rivalry to accountability: Psychoanalytic reflections on restorative justice}

Abstract: A number of interventions have included horizontal relationships betting on the circulation of the word as a condition for inscribing a distance able to produce a closer bond with the other. This article considers the functions of the other, addresses the relationship with similar others by highlighting the elements raised by Lacan in Hamlet and demonstrating that it is beyond the rivalry with similar others that the fulfilment of Hamlet's desire (Lacan, 1959/86) enters the game. Our strategy will be the presentation of two scenes of intervention with adolescents in conflict with the law, one of whom in a process of restorative justice. We shall take the consequences of this analysis regarding the possibility and conditions of horizontality in the relations, particularly in interventions with adolescents in conflict with the law, aiming at responsibility as a construction which operates in the encounter with the other.

Keywords: psychoanalysis, restorative justice, adolescents in conflict with the law, responsibility, similar other.

\section{De la rivalité à la responsabilité: réflexions sur la justice réparatrice de la psychanalyse}

Résumé: Plusieurs modalités d'intervention incluent les relations horizontales qui de son côté investissent à la circulation de la parole comme condition d'inscription d'une distance capable d'approcher et de produire des liens avec l'autre. Dans ce travail nous allons aborder les fonctions de l'autre, la relation avec le semblable, soulevant les éléments travaillés par Lacan dans Hamlet, pour démontrer que c'est au-delà de la rivalité au semblable qui se joue la réalisation du désir dans Hamlet (Lacan, 1959/86). Dans ce sens, la stratégie se déroulera par la présentation de deux scènes d'intervention auprès des adolescents en conflit avec la loi, dont une est en processus de Justice Réparatrice. Les conséquences de cette analyse seront basées par les possibilités et les conditions d'horizontalité dans les relations, particulièrement dans les interventions auprès des adolescents en conflit avec la loi, étant donné la responsabilité comme une construction qui opère dans la rencontre avec l'autre.

Mots-clés: psychanalyse, justice réparatrice, adolescents en conflit avec la loi, responsabilité, semblable.

\section{De la rivalidad a la responsabilidad: reflexiones sobre la justicia restaurativa a partir del psicoanálisis}

Resumen: Varios tipos de intervención han incluido las relaciones horizontales que apostan en la circulación de la palabra como condición para la inscripción de uma distancia capaz de producir una unión más estrecha com el otro. En este trabajo, consideramos las funciones del otro, abordamos la relación con otros semejantes destacando los elementos planteados por Lacan en Hamlet, y demonstrando que más allá de la rivalidad con otros semejante entra en el juego el cumplimento del deseo de Hamlet (Lacan, 1959/86 ). Nuestra estrategia será la presentación de la intervención de dos escenas con adolescentes en conflicto con la ley, uno de los quales en un proceso de justicia restaurativa. Tomaremos las consecuencias de este análisis considerando la posibilidad y las condiciones de las relaciones horizontales, sobre todo en las intervenciones con adolescentes en conflicto con la ley, en vista de la responsabilidad como una construcción que opera en el encuentro con el otro.

Palabras clave: psicoanálisis, justicia restaurativa, adolescentes en conflicto con la ley, responsabilidad, semejantes.

\section{Referências}

Chatelard, D. S. (2001). Algumas considerações sobre o termo afầnise a partir de E. Jones e J. Lacan. Ágora, 4(2), 51-59. Recuperado de http://dx.doi.org/10.1590/S151614982001000200004

Freud, S. (1980a). Sobre o narcisismo: uma introdução. In S. Freud, Edição standard das obras psicológicas completas de Sigmund Freud (Vol. 14, pp. 89-122). Rio de Janeiro, RJ: Imago. (Trabalho original publicado em 1914)

Freud, S. (1980b). Luto e melancolia. In S. Freud, Edição standard das obras psicológicas completas de Sigmund Freud (Vol. 14, pp. 275-292). Rio de Janeiro, RJ: Imago. (Trabalho original publicado em 1917)
Freud, S. (1980b). Ego e o Id. In S. Freud, Edição standard das obras psicológicas completas de Sigmund Freud (Vol. 19, pp. 23-75). Rio de Janeiro, RJ: Imago. (Trabalho original publicado em 1923)

Lacan, J. (1974-1975). Seminário R. S. I. (Trabalho inédito).

Lacan, J. (1978). Escritos. São Paulo, SP: Perspectiva.

Lacan, J. (1986). Hamlet por Lacan. In Textos psicanalíticos (vol. 1, p. 75). São Paulo, SP: Escuta. (Trabalho original publicado em 1959)

Lacan, J. (1998). A agressividade em psicanálise. In J. Lacan, Escritos (pp. 104-126). Rio de Janeiro, RJ: Jorge Zahar. (Trabalho original publicado em 1948) 
Lacan, J. (2002). O Seminário. Livro 6: O desejo e sua interpretação (Publicação não comercial de circulação interna da Associação Psicanalítica de Porto Alegre. Trabalho original publicado em 1958-1959)

Lacan, J. (2008) O Seminário. Livro 16: De um outro ao outro. Rio de Janeiro, RJ: Jorge Zahar. (Trabalho original publicado em 1968-1969)
Rosa, M. D., Vicentin, M. C., \& Catroli, V. (2009). Viver em tempos sombrios: do gozo à experiência compartilhada. Psicologia em Revista, 2, 51-68.

Safouan, M. (2006). Lacaniana I: os seminários de Jacques Lacan (1953-1963). Rio de Janeiro, RJ: Companhia de Freud.

Recebido: 02/05/2013

1a revisão: $02 / 10 / 2013$

Aceito: $29 / 11 / 2013$ 
